\title{
The effect of different composition of ternary mixtures of emulsifying salts on the consistency of processed cheese spreads manufactured from Swiss-type cheese with different degrees of maturity
}

\author{
R. N. Salek, M. Černíková, S. Maděrová, L. Lapčík, and F. Buňka ${ }^{1}$ \\ Department of Food Technology, Faculty of Technology, Tomas Bata University in Zlín, T. G. Masaryka 5555, 760 01, Zlín, Czech Republic
}

\begin{abstract}
The scope of this work was to investigate the dependence of selected textural (texture profile analysis, TPA) and viscoelastic properties of processed cheese on the composition of ternary mixtures of emulsifying salts [disodium hydrogenphosphate, DSP; tetrasodium diphosphate, TSPP; sodium salt of polyphosphate (with mean length $\mathrm{n} \approx 20$ ), P20; and trisodium citrate, TSC] during a 60 -d storage period $\left(6 \pm 2^{\circ} \mathrm{C}\right)$. The processed cheese samples $[40 \% \mathrm{wt} / \mathrm{wt}$ dry matter (DM) content, $50 \%$ wt/wt fat in DM content] were manufactured using Swiss-type cheese (as the main raw material) with 4 different maturity degrees $(4,8,12$, and 16 wk of ripening). Moreover, the $\mathrm{pH}$ of the samples was adjusted (the target values within the range of 5.60-5.80), corresponding to the standard $\mathrm{pH}$ values of spreadable processed cheese. With respect to the individual application of emulsifying salts (regardless of the maturity degree of the Swiss-type cheese applied), the samples prepared with P20 were the hardest, followed by those prepared with TSPP, TSC, and DSP. Furthermore, a specific ratio of DSP:TSPP (1:1) led to a significant increase in the hardness of the samples. On the whole, the hardness of all processed cheese samples increased with the prolonging storage period, whereas their hardness significantly dropped with the rising ripening stage of the raw material utilized. In all of the cases, the trends of hardness development remained analogous, and only the absolute values differed significantly. Moreover, the findings of TPA were in accordance with those of the rheological analysis. In particular, the specific ratio of DSP:TSPP (1:1) resulted in the highest gel strength and interaction factor values, followed by P20, TSPP, TSC, and DSP (used individually), reporting the same trend which was demonstrated by TPA. The monitored values of the gel strength and interaction factor decreased with the increasing maturity degree of the Swiss-type cheese used. The intensity of the rigid-
\end{abstract}

Received June 29, 2015.

Accepted December 30, 2015

${ }^{1}$ Corresponding author: bunka@ft.utb.cz ity of the samples showed an analogous relationship to the intensity of the gel strength; the higher the gel strength of the sample, the more inflexible the product is expected to be.

Key words: Swiss-type cheese, processed cheese, sodium salt of phosphates, sodium salt of citrate, rheology

\section{INTRODUCTION}

Processed cheese $(\mathbf{P C})$ is a multicomponent dairy complex system described as stable oil-in-water emulsion (Lee et al., 2003; Chen and Liu, 2012; Hanaei et al., 2015). The multilaterism of PC derives from the fact that it contains a wide variety of interacting components and a high water content (Marchesseau et al., 1997). Therefore, its matrix is formed by blending shredded cheese (of different types and maturity degrees) in the presence of emulsifying salts (ES; mainly sodium salts of phosphates, polyphosphates, citrates, or a combination of these), heated under partial vacuum and constant stirring, resulting in a homogeneous and smooth mass with desired properties (Guinee et al., 2004; Lee et al., 2004; Sádlíková et al., 2010; Chen and Liu, 2012).

Cheese ripening is the term describing a technological process during which biochemical and microbiological changes occur in cheese (raw material for PC manufacturing), resulting in the development of a specific flavor and consistency in the matured product (Pachlová et al., 2012; Ochi et al., 2013). The degree of casein proteolysis in the cheese applied during PC manufacture is a parameter that significantly influences its textural and viscoelastic properties (Piška and Štetina, 2004; Brickley et al., 2007; Buňka et al., 2013).

The consistency of PC can be affected by many factors, including the type, composition, and chemical profile of the cheese used (DM, fat, protein, and calcium ion content, and maturity degree), the type and concentration of ES, the presence and concentration of ions (especially calcium, sodium, and potassium), other optional dairy and nondairy ingredients, the $\mathrm{pH}$ of the mass to be melted, the processing and storage 
conditions (processing and storage temperature, stirring speed, time and temperature of the fusion, and cooling rate) and a possible use of some hydrocolloids (Shirashoji et al., 2006; Dimitreli and Thomareis, 2007; Gustaw and Mleko, 2007). Moreover, ES are ingredients of great importance in PC manufacture. Their ability to sequester calcium in the cheese matrix leads to the enhancement of casein emulsifying properties; the replacement of calcium from the insoluble calciumparacaseinate (present in cheese) with sodium results in the formation of soluble sodium-paracaseinate, which can easily be dispersed and thus considerably influence the emulsification of fat (casein coats the surfaces of the dispersed free fat globules) and water stabilization within the matrix formed (Kawasaki, 2008; Chen and Liu, 2012; Buňka et al., 2014).

Furthermore, PC with diverse consistency and alternative functional properties may be manufactured as a result of the use of different types (phosphate, citrate, or both) and combinations of ES. In practice nowadays, the individual application of ES is very rare. In fact, ES are applied in ternary or even more componential mixtures (Guinee et al., 2004; Kapoor and Metzger, 2008; Salek et al., 2015). Generally, the effect of different composition of ternary mixtures of the individual sodium salts of phosphates (especially disodium hydrogenphosphate, tetrasodium diphosphate, and sodium salt of polyphosphate) has been described in the papers by Weiserová et al. (2011) and Buňka et al. (2012,2013), but only for Dutch-type cheese as the raw material for the PC tested. Swiss-type cheese (STC) is a group of hard or semi-hard cheeses in texture, with desired propionic acid fermentation caused by propionic acid bacteria (especially Propionibacterium freudenreichii ssp. freudenreichii and Propionibacterium freudenreichii ssp. shermanii). Therefore, their flavor is characterized as sweet and nut-like. This is due to free fatty acids, peptides, AA, carbonyls, or their mutual interactions (Paulsen et al., 1980; Beuvier et al., 1997; Bouton et al., 2009). However, in the available literature, no existing study delineates PC manufacture using STC as the main raw ingredient. Swiss-type cheese is often used as part of the raw material for PC manufacture. On the other hand, the individual usage of STC in PC production has not been described. The influence of different maturity degrees of STC associated with different combinations of ES ternary mixtures affecting PC consistency has not been found in the literature.

The first aim of this study was to explore the dependence of selected textural properties (especially hardness, cohesiveness, and relative adhesiveness) and viscoelastic properties of $\mathrm{PC}$ on the composition of ternary mixtures of ES containing disodium hydrogenphosphate $\left(\mathrm{Na}_{2} \mathrm{HPO}_{4}, \mathbf{D S P}\right)$, tetrasodium diphosphate
$\left(\mathrm{Na}_{2} \mathrm{P}_{2} \mathrm{O}_{7}\right.$, TSPP), sodium salt of polyphosphate with mean length $\mathrm{n} \approx 20$ (P20), and trisodium citrate $\left(\mathrm{C}_{2} \mathrm{H}_{5} \mathrm{Na}_{3} \mathrm{O}_{7}\right.$, TSC) during a 60 -d storage period. The above-mentioned dependence was observed in samples with adjusted $\mathrm{pH}$ values (target values within the interval of 5.60-5.80) corresponding to the standard $\mathrm{pH}$ values of PC spreads. The second aim was to investigate the effect of different maturity degrees of the STC (basic raw material) on the above-mentioned dependence.

\section{MATERIALS AND METHODS}

\section{Manufacture of PC Samples}

For the manufacture of the model PC samples with $40 \%$ (wt/wt) DM content and 50\% (wt/wt) fat in DM, the following materials were used: STC block $(60 \%$ wt/wt DM content, $30 \%$ wt/wt fat DM content; 4,8 , 12 , and 16 wk of ripening; the same raw materials of STC were used in the whole experiment; MoraviaLacto, a.s., Jihlava, Czech Republic), butter ( $84 \%$ wt/ wt DM content, $82 \%$ wt/wt fat content; Sachsenmilch Leppersdorf, GmbH, Wachau, Germany), water and ternary mixtures of DSP, TSPP, P20 (Fosfa PLC Company, Břeclav, Poštorna, Czech Republic), and TSC (SigmaAldrich Inc., St. Louis, MO). Moreover, the ES were applied into 4 types of ternary mixtures comprising DSP:TSC:P20, DSP:TSPP:TSC, TSC:TSPP:P20, and DSP:TSPP:P20. The total concentration of the ternary mixtures mentioned above was $3 \%$ (wt/wt) of the total weight of the melt. Each type of the ternary mixture was tested in 12 reciprocal percentage ratios (100:0:0; 50:50:0; 0:100:0; 40:40:20; 40:20:40; 20:40:40; $50: 0: 50 ; 0: 50: 50 ; 40: 0: 60 ; 20: 20: 60 ; 0: 40: 60 ; 0: 0: 100)$; the percentage of the components was estimated on the basis of the total weight of ES (total weight $=100 \%$ ). Each combination of the ES formulation was made in duplicate resulting in 96 lots in total (4 types of ternary mixtures $\times 12$ reciprocal percentage ratios $\times 2$ repetitions). The scheme of the experiment design is shown in Figure 1. A Vorwerk Thermomix TM 31-1 blender cooker (Vorwerk \& Co. Thermomix, GmbH, Wuppertal, Germany) with indirect heating was employed for the manufacture of the PC samples. The same apparatus was also used for a contiguous scope in the work by Lee et al. (2004, 2013) and Buňka et al. (2013). The manufacturing procedure was described in detail in the work by Buňka et al. (2013) and Salek et al. (2015). Briefly, a target temperature of $90^{\circ} \mathrm{C}$ was held for 1 min (the total melting time was 10-12 min) at approximately $2,750 \times g$. Therefore, the $\mathrm{pH}$ of the samples was adjusted (target values within the interval of 5.60-5.80) using acid or alkali ( $1 \mathrm{~mol} / \mathrm{L}$ of $\mathrm{HCl}$ or $\mathrm{NaOH})$. According to a pilot study (unpublished data) the calculated 
amount of acid/alkali was added when the temperature approached 85 to $86^{\circ} \mathrm{C}, 30$ to $50 \mathrm{~s}$ before reaching the melting point (Buňka et al., 2013; Salek et al., 2015). The hot melt was poured into polypropylene doses of cylindrical shape $(52 \mathrm{~mm}$ in diameter and $50 \mathrm{~mm}$ high). Consequently, to maintain the values of DM and fat in DM without changes, the addition of water was reduced (by the calculated amount of acid/alkali). The $\mathrm{PC}$ samples were cooled and stored at $6 \pm 2^{\circ} \mathrm{C}$ until the analyses were performed. The analyses were performed on $\mathrm{d} 2,9,30$, and 60 of storage, with the exception of oscillation rheology, which was performed on d 30 (a typical period of PC storing). Each PC (manufactured from STC of certain maturity) was produced twice.

\section{Basic Chemical Analysis of PC Samples}

The DM content of the PC samples was gravimetrically determined according to ISO (2004). Moreover, the $\mathrm{pH}$ values were measured at ambient temperature using a glass tip electrode of a $\mathrm{pH}$ meter (pHSpear, Eutech Instruments, Oakton, Malaysia) by direct insertion of the spear into the PC samples at 3 randomly selected spots (in each pot).

\section{Free Amino Acid Content of STC (Raw Material)}

Before the analysis of free amino acid (FAA) content, the samples of the individual STC with different degrees of maturity $(4,8,12$ and 16 wk of ripening) were submitted to lyophilisation using the Christ Alpha 1-4 (Christ, Osterode, Germany) equipment and then stored at $-80^{\circ} \mathrm{C}$. All measurements were performed using the AAA 400 Amino Acid Analyzer (Ingos, Prague, Czech Republic) - ion-exchange chromatography apparatus according to the protocol described by Buňková et al. (2009) and Pachlová et al. (2011). The FAA content was calculated as a sum of 22 individual FAA and

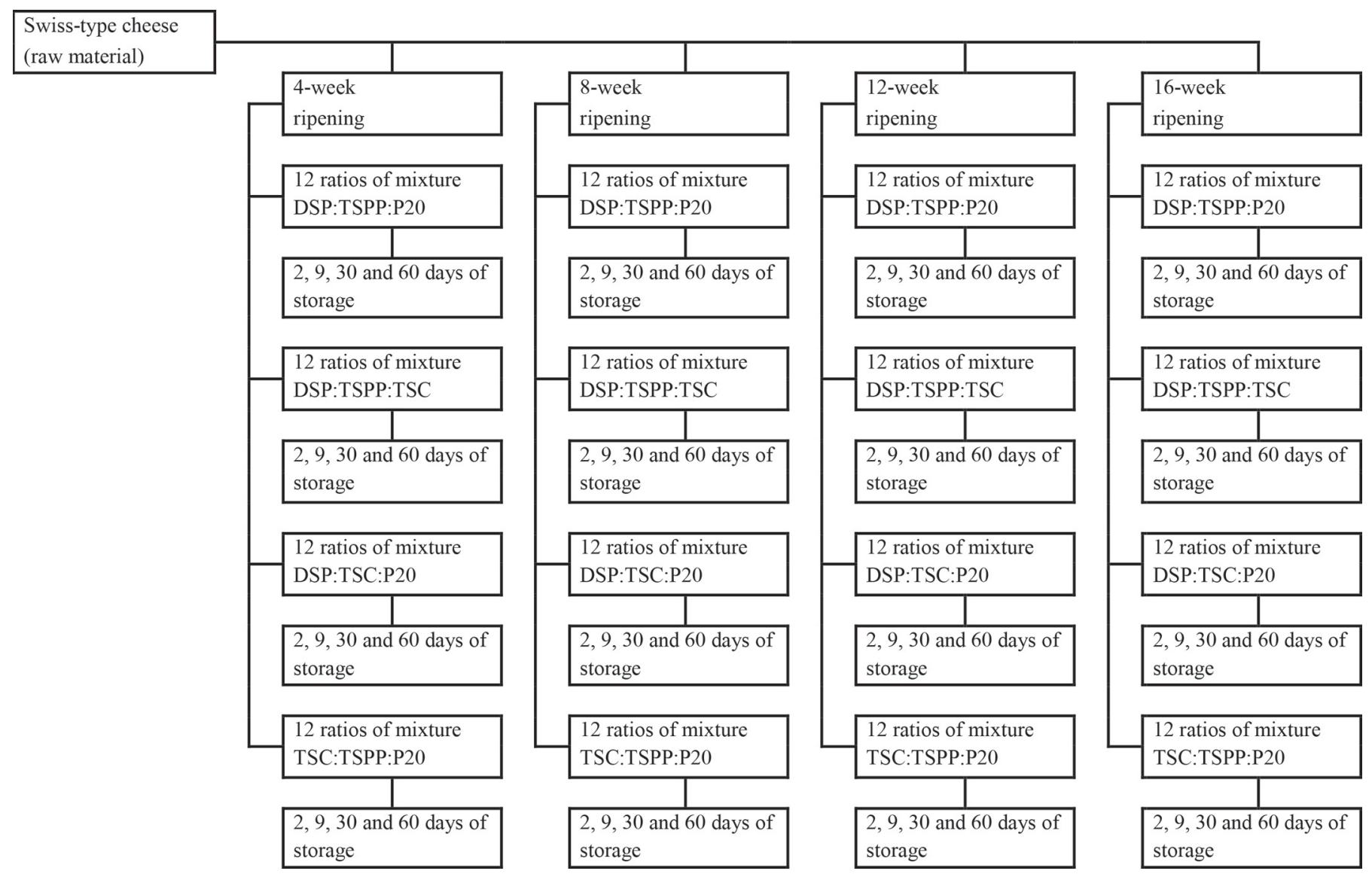

Figure 1. Scheme of the experimental design with model processed cheeses manufactured using Swiss-type cheese (in various time of ripening) and the different percentage ratios (100:0:0, 50:50:0, 0:100:0, 40:40:20, 40:20:40, 20:40:40, 50:0:50, 0:50:50, 40:0:60, 20:20:60, 0:40:60, 0:0:100) of the 4 types of ternary mixtures consisting of DSP:TSPP:P20, DSP:TSPP:TSC, DSP:TSC:P20, and TSC:TSPP:P20 (DSP, disodium hydrogenphosphate; TSPP, tetrasodium diphosphate; P20, sodium salt of polyphosphate with mean length $\mathrm{n} \approx 20$; and TSC, trisodium citrate). The model samples were tested after $2,9,30$, and $60 \mathrm{~d}$ of storage. 
the content of similar substances ( $\gamma$-aminobutyric acid, alanine, aspartic acid, asparagine, arginine, citrulline, cysteine, glutamic acid, glutamine, glycine, histidine, isoleucine, leucine, tyrosine, lysine, methionine, ornithine, phenylalanine, proline, serine, threonine, valine). Each cheese (raw material) was lyophilisated twice, each lyophilisate was extracted twice and each extract was loaded on the column in triplicate $(\mathrm{n}=12)$.

\section{Texture Profile Analysis}

The TPA method was performed for the evaluation of selected textural properties of the PC samples (hardness, cohesiveness, and relative adhesiveness) using a TA.XTplus texture analyzer (Stable Micro Systems Ltd., Godaming, UK). The tests were carried out at 6 $\pm 2^{\circ} \mathrm{C}$ (the sample measurement was performed immediately after removing them from a refrigerator where they were stored) after 2, 9, 30, and $60 \mathrm{~d}$ of storage according to the methodology described by Piska and Štětina (2004), Weiserová et al. (2011), and Sołowiej et al. (2014). During the measurements, 2 successive penetration events were implemented on the samples to ensure $25 \%$ deformation by a $20-\mathrm{mm}$ cylindrical probe $\mathrm{P} 20$; the rate of the penetration was $2 \mathrm{~mm} \cdot \mathrm{s}^{-1}$ and the trigger force was $5 \mathrm{~g}$. The results obtained were recorded as force-displacement/time curves describing the force (N) needed to deform the sample proportionally with time. On each day of the analysis, each variant of the ternary mixtures was measured in triplicate $(n=6)$.

\section{Rheological Analysis}

The rheological analysis of the $\mathrm{PC}$ samples on $\mathrm{d} 30$ of storage $\left(6 \pm 2^{\circ} \mathrm{C}\right)$ was performed using a dynamic oscillatory shear rheometer (RheoStress 1, HAAKE, Bremen, Germany). Additionally, to describe the changes in the viscoelastic properties of the solidified melt mass, a plate-plate geometry (35 $\mathrm{mm}$ in diameter) was selected in dependence with frequency ( $\omega$; ranging from 0.01 to $100.00 \mathrm{~Hz}$ ) at $20 \pm 0.1^{\circ} \mathrm{C}$. The selected monitored parameters, including elastic or storage $\left(\mathrm{G}^{\prime}\right)$ and viscous or loss $\left(\mathrm{G}^{\prime \prime}\right)$ moduli (determined as a function of frequency), were used for complex modulus $\left(G^{*}\right)$ calculation according to equation [1]:

$$
G^{*}=\sqrt{\left(G^{\prime}\right)^{2}+\left(G^{\prime \prime}\right)^{2}} .
$$

Winter's critical gel theory was implemented to evaluate the changes in the viscoelastic properties of the PC samples. According to the following equation [2], the complex modulus can be expressed as follows (Winter and Chambon, 1986; Gabriele et al., 2001; Macků et al., 2009):

$$
G^{*}(\omega)=\mathrm{A}_{\mathrm{F}} \cdot \omega^{1 / \mathrm{z}}
$$

where $A_{F}$ is the strength of the gel $\left(\mathrm{Pa} \cdot \mathrm{s}^{1 / \mathrm{z}}\right)$ and $\mathrm{z}$ is the interaction factor (defined as the number of structural units interacting with one another in a 3-dimensional network; unitless). The higher the interaction factor is, the more interactions occur in the matrix of the sample (Gabriele et al., 2001; Martínez-Ruvalcaba et al., 2007; Macků et al., 2009). The reported values were the mean of at least 4 replicates $(n=8)$.

\section{Statistical Analysis}

Nonparametrical analyses of variance of KruskalWallis and Wilcoxon tests were used to evaluate the results obtained (Unistat 6.5 software, Unistat, London, UK; the significance level was 0.05). One-way tests were used, and therefore (1) the differences between the samples with a different ratio of ES (samples manufactured using raw material at a constant level of ripening at a constant time of storage) in the ternary mixture; (2) the differences between the samples with various times of STC ripening (samples with a constant ratio of ES in each ternary mixture type at a constant time of storage); and (3) the differences between the samples with various times of storage (samples with a constant ratio of ES in each ternary mixture type manufactured using raw material with a constant level of ripening) were evaluated independently. For the estimation of the gel strength and the interaction factor, nonlinear regression analysis (nonlinear least squares regression) was used for the following conditions: $A_{F}>0$ and $\mathrm{z}$ $\geq 0$. The Marquardt-Levenburg method was applied (Unistat 6.5 software was also applied).

\section{RESULTS}

\section{Basic Chemical Analysis of PC Samples and FAA Content of STC (Raw Material)}

The DM levels of all samples were within the interval of 40.16 to $41.12 \%$, depicting the stability of the DM content of the samples. Furthermore, another significant factor affecting the viscoelastic properties of $\mathrm{PC}$ is $\mathrm{pH}$. The $\mathrm{pH}$ value adjustment resulted in $\mathrm{PC}$ samples with $\mathrm{pH}$ values ranging from 5.61 to 5.78 , which can be characterized as acceptable for spreadable PC. The proteolytic changes occurring during cheese ripening were examined by the development of FAA content. The FAA concentrations of the STC (raw material) 
after $4,8,12$, and 16 wk of ripening were 17.49, 28.27, 38.48 , and $44.75 \mathrm{~g} \cdot \mathrm{kg}^{-1}$, respectively.

\section{Texture Profile Analysis}

The results of PC hardness are presented in Figures 1-4. With respect to the individual ES application and regardless of the maturity degree of the treated STC, the samples prepared with P20 were the hardest $(P$ $<0.05)$. Moreover, the samples manufactured with TSC were harder than those manufactured with DSP and similarly hard to those manufactured with TSPP. The development of PC hardness, depending on the composition of ES ternary mixtures (composed of DSP, TSPP, and P20) and on the ripening stage $(4,8,12$, and 16 wk of maturity) of the STC applied after 2, 9, 30 , and $60 \mathrm{~d}$ of storage at $6 \pm 2^{\circ} \mathrm{C}$ is interpreted in Figure 2. Furthermore, a specific ratio of DSP:TSPP (1:1) was distinguished, leading to a considerable increase in hardness of the samples $(P<0.05)$. Nonetheless, with the increasing proportion of P20 in the ternary mixture, the effect of the above-mentioned ratio significantly decreased $(P<0.05)$. However, when P20 was present in the ES ternary mixture at levels $\geq 50 \%$, the influence of the above-mentioned ratio on the hardness of the samples became insignificant $(P \geq 0.05)$. Figure 3 illustrates the hardness values of the $\mathrm{PC}$ samples of the ternary mixture of DSP, TSPP, and TSC depending on the maturity degree of the raw material and on the storage period of the samples obtained $(2,9,30$, and $60 \mathrm{~d}$ at $6 \pm 2^{\circ} \mathrm{C}$ ). Additionally, the same phenomenon as in the previous case (Figure 2) was noticed due to the subsistence of the specific ratio of DSP:TSPP (1:1). Furthermore, firmer PC samples were obtained with TSPP and TSC at a ratio of 1:1 (Figure 3) when the proportion of DSP in the ternary mixtures of ES was at zero concentrations $(P<0.05)$. In addition, any deviation from the previously mentioned ratio (TSPP:TSC, 1:1) led to a significant decrease in hardness $(P<0.05)$. The hardness of the PC samples decreased with the increasing proportion of DSP in the ternary mixtures $(P<0.05)$.

Figure 4 shows the values of hardness in the PC samples of the ternary mixture consisting of DSP, TSC, and P20 depending up the maturity degree of the raw material and the storage period of the product samples. The rising proportion of TSC and P20 (with a reduction in DSP) resulted in the increasing hardness of the $\mathrm{PC}$ samples. Moreover, comparing the effect of TSC and P20, the effect of P20 in the ternary mixture evoked a greater increase in the hardness of the samples. In the case of the ternary mixtures of ES composed of TSC, TSPP, and P20 (Figure 5), the harder samples were detected when TSC and TSPP were applied at a ratio of $1: 1$ and in the absence of P20 in the ternary mixture $(P<0.05)$. Nevertheless, when the proportion of P20 was gradually increased in the mixture, the hardness of the PC samples presented a slightly rising trend.

The main results obtained can be summarized as follows: the hardness of all PC samples increased with the prolonging storage period, regardless of the ternary mixture applied and the maturity degree of the STC. By the same token, it can be depicted that the hardness of all samples decreased with the increasing ripening stage of the STC used, regardless of the ES ternary mixture applied. Likewise, in all cases, the trends of hardness of the PC samples remained analogous; only the absolute values of firmness differed significantly $(P$ $<0.05)$. The more unripe the STC applied, the harder the samples were observed.

The development of cohesiveness and relative adhesiveness was insignificant in terms of the application of the ternary mixtures of ES $(P \geq 0.05)$. Nevertheless, the adhesiveness values increased depending on the maturity degree of the cheese (raw material), whereas the values of cohesiveness decreased. The values of relative adhesiveness of the samples prepared using STC with $4,8,12$, and 16 wk of ripening were 0.11 to $0.17,0.22$ to $0.24,0.25$ to 0.27 , and 0.28 to 0.29 , respectively (the values are shown as the interval of $d 2$ to 60 of the analysis; N). Moreover, the values of cohesiveness of the samples prepared using STC with 4, 8, 12, and 16 wk of ripening were 0.50 to $0.54,0.46$ to $0.47,0.44$ to 0.47 , and 0.33 to 0.35 , respectively (the values are shown as the interval of $d 2$ to 60 of the analysis).

\section{Rheological Analysis}

Figure 6 illustrates the dependence of the complex modulus $\left(\mathrm{G}^{*}\right)$ on frequency (in range of $0.01-100.00$ $\mathrm{Hz}$ ) for selected $\mathrm{PC}$ samples (after $30 \mathrm{~d}$ of storage at 6 $\pm 2^{\circ} \mathrm{C}$ ) manufactured by applying STC as raw material with different maturity degrees $(4,8,12$, and $16 \mathrm{wk}$ of maturity). Moreover, for these measurements DSP, TSPP, TSC, P20, and DSP:TSPP (in a ratio of 1:1) were used individually as ES. According to Figure 6, in all of the cases the complex modulus $\left(\mathrm{G}^{*}\right)$ increased in the whole frequency range tested. Correspondingly, these results indicate that each ES (phosphate, citrate, or their combination) has a unique effect on the rheological properties of PC. The above-mentioned results were also evaluated by the data obtained from Winter's critical gel theory, where the gel strength $\left(\mathrm{A}_{\mathrm{F}}\right)$ and the interaction factor $(\mathrm{z})$ were estimated from the complex modulus $\left(\mathrm{G}^{*}\right)$ according to the equation 2 and are illustrated in Tables 1 and 2. The findings are in harmony 
with the results of TPA mentioned above. Above all, the specific ratio of DSP:TSPP (1:1) was also identified, resulting in the highest gel strength and interaction factor values, followed by P20, TSPP, TSC, and DSP, respectively, reporting the same trend that was demonstrated by TPA. Similarly, the ratio of TSPP:TSC (1:1) was recognized leading to a significant rise in the data obtained from Winter's critical gel theory. Last but not least, the values of the gel strength and the interaction factor decreased with the increasing maturity degree of the STC used. Therefore, it could be assumed that the higher the gel strength of the sample, the more rigid product can be expected $(P<0.05)$.

\section{DISCUSSION}

The key factors influencing the PC properties are mainly ES (type and amount), the type and maturity degree of the cheese used (as raw material), and the processing and storage conditions. The DM content and $\mathrm{pH}$ values of the $\mathrm{PC}$ samples tested were in narrow intervals, which is crucial for maintaining the comparability of the PC studied (Marchesseau et al., 1997; Lee and Klostermeyer, 2001; Lee et al., 2004; Piska and Štětina, 2004). In addition, because the cheese maturity degree is a term closely related to the extent of proteolysis in cheese during ripening, it plays an important

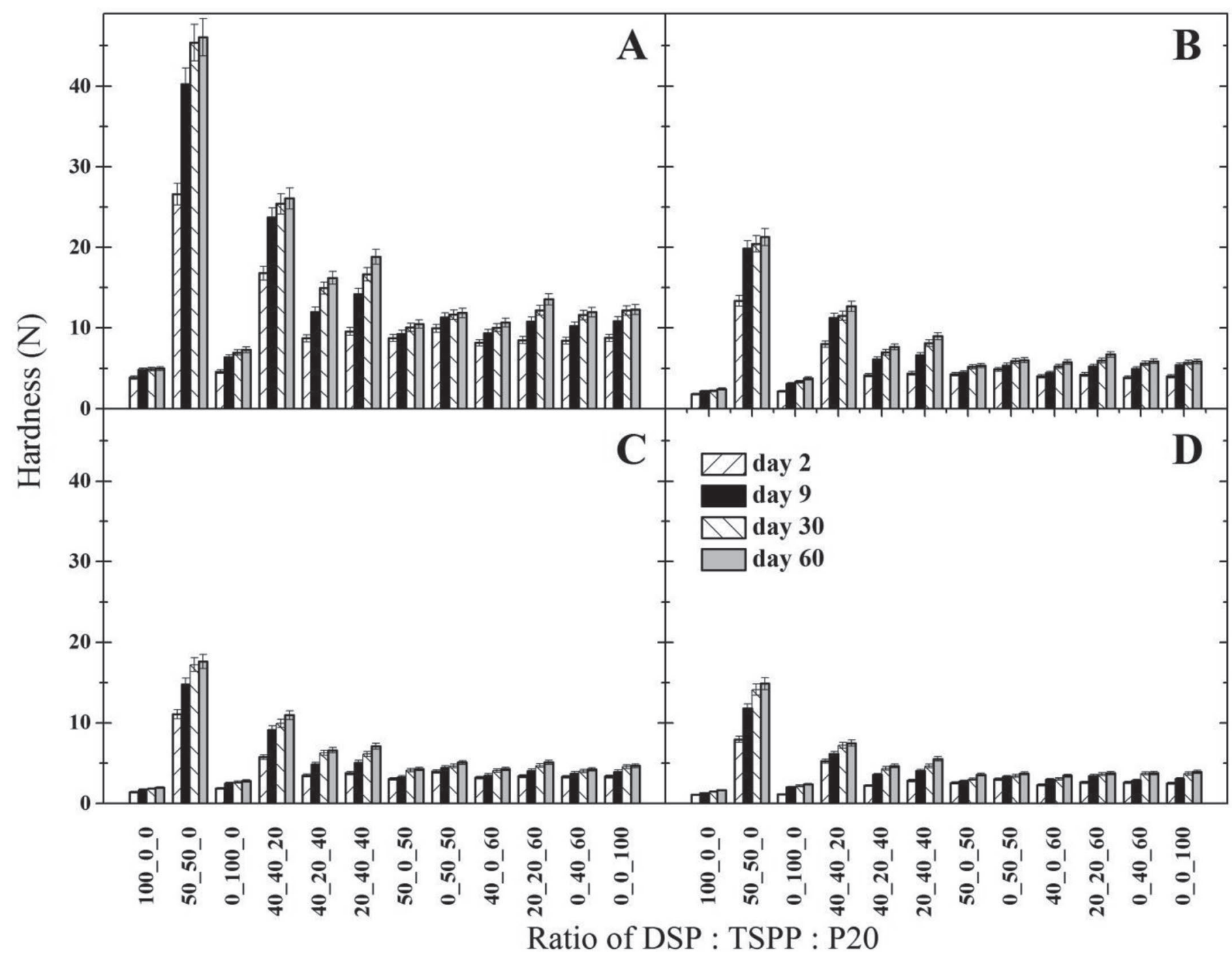

Figure 2. The dependence of processed cheese hardness (calculated as maximum force during the first penetration cycle; N) on the relative amount (in percentage; percentage of ternary mixtures was calculated on the total weight of emulsifying salts $=100 \%$; axis $\mathrm{x}$ ) of disodium phosphate (DSP), tetrasodium diphosphate (TSPP), and sodium salt of polyphosphate (P20) in a ternary mixture of emulsifying salts during $60 \mathrm{~d}$ of storage at $6^{\circ} \mathrm{C}[\mathrm{n}=6$; the results were expressed as means (columns) \pm standard deviations (bars); processed cheeses were sampled after 2, 9, 30, and $60 \mathrm{~d}$ of storage]. Processed cheeses were made from Swiss-type cheese after different times of ripening (part A, 4 wk; part B, 8 wk; part C, $12 \mathrm{wk}$; part D, $16 \mathrm{wk})$. 
role in determining its textural and sensory properties. Thus, the concentrations of FAA (in the raw material) showed a clear tendency to increase with the ripening period as expected, because during proteolysis these compounds were released by the proteolytic agents, mainly by microbial enzymes, through the biochemical reactions evolving during cheese ripening (Hayaloglu et al., 2004; Ji et al., 2004; Poveda et al., 2004). These results agree with those of Vicente et al. (2001), Bustamante et al. (2003), and Pachlová et al. (2011), who reported a significant response between the FAA content and the ripening time. Based on our results, regardless of the maturity degree of the STC applied and the storage period of the samples obtained, the sole application of phosphate ES with longer length chains resulted in increasing hardness of the samples. However, the individual application of TSC led to similar results in hardness as that of TSPP. On the whole, it can be generalized that the sole application of ES resulted in rising hardness of the samples in the following order: DSP $<$ TSC $\approx$ TSPP $<$ P20. The same trend was reported by El-Bakry et al. (2011), Weiserová et al. (2011), and Nagyová et al. (2014). This could be explained by the fact that phosphates of longer chain length affect the ion-exchange intensity (of sodium ions for calcium ions). Moreover, this intensity (of ion-

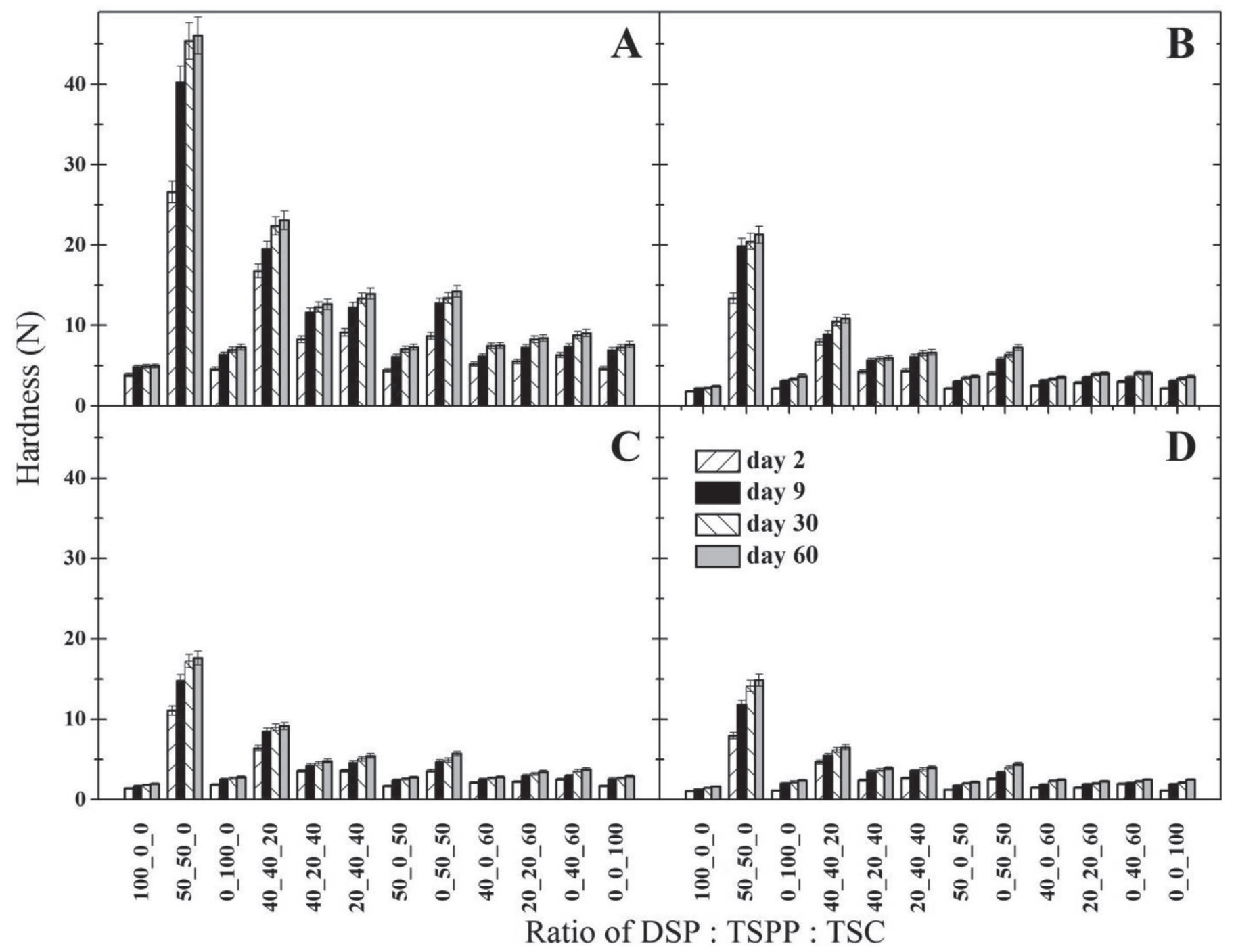

Figure 3. The dependence of processed cheese hardness (calculated as maximum force during the first penetration cycle; N) on the relative amount (in percentage; percentage of ternary mixtures was calculated on the total weight of emulsifying salts $=100 \%$; axis $\mathrm{x}$ ) of disodium phosphate (DSP), tetrasodium diphosphate (TSPP), and trisodium citrate (TSC) in a ternary mixture of emulsifying salts during $60 \mathrm{~d}$ of storage at $6{ }^{\circ} \mathrm{C}[\mathrm{n}=6$; the results were expressed as means (columns) \pm standard deviations (bars); processed cheeses were sampled after 2, 9, 30, and $60 \mathrm{~d}$ of storage]. Processed cheeses were made from Swiss-type cheese after different times of ripening (part A, 4 wk; part B, 8 wk; part C, 12 wk; part D, $16 \mathrm{wk})$. 
exchange) is increasing with the dispersion of casein intensity, resulting from the ES addition (Mizuno and Lucey, 2007; Dimitreli and Thomareis, 2009; Buňka et al., 2013). According to the previous studies, the PC matrix formation is in close dependence with casein dispersion in the system tested (Dimitreli and Thomareis, 2009; Cunha et al., 2013). Therefore, a higher degree of casein dispersion enhances casein developing their hydrating and emulsifying abilities; the latter abilities increase the intensity of interactions in the melt (El-Bakry et al., 2011; Kaliappan and Lucey, 2011). In general, it can be assumed that PC with higher values of hardness was obtained when the ternary mixture of
ES applied was composed of salts with more intensive ability to disperse casein. The samples prepared with the addition of binary mixture of DSP:TSPP (in a ratio of 1:1) resulted in products with the highest values of hardness (regardless of the maturity degree of the STC tested). A possible explanation of this phenomenon, reported by Mizuno and Lucey (2007) and Buňka et al. (2013), could be the ability of diphosphates to enhance the gel formation ability of casein. However, insufficient concentrations of disphosphates may lead to the formation of very weak gels (Mizuno and Lucey, 2007). Moreover, another possible explanation of the significance of DSP:TSPP specific ratio (1:1) was reported by Kaliap-

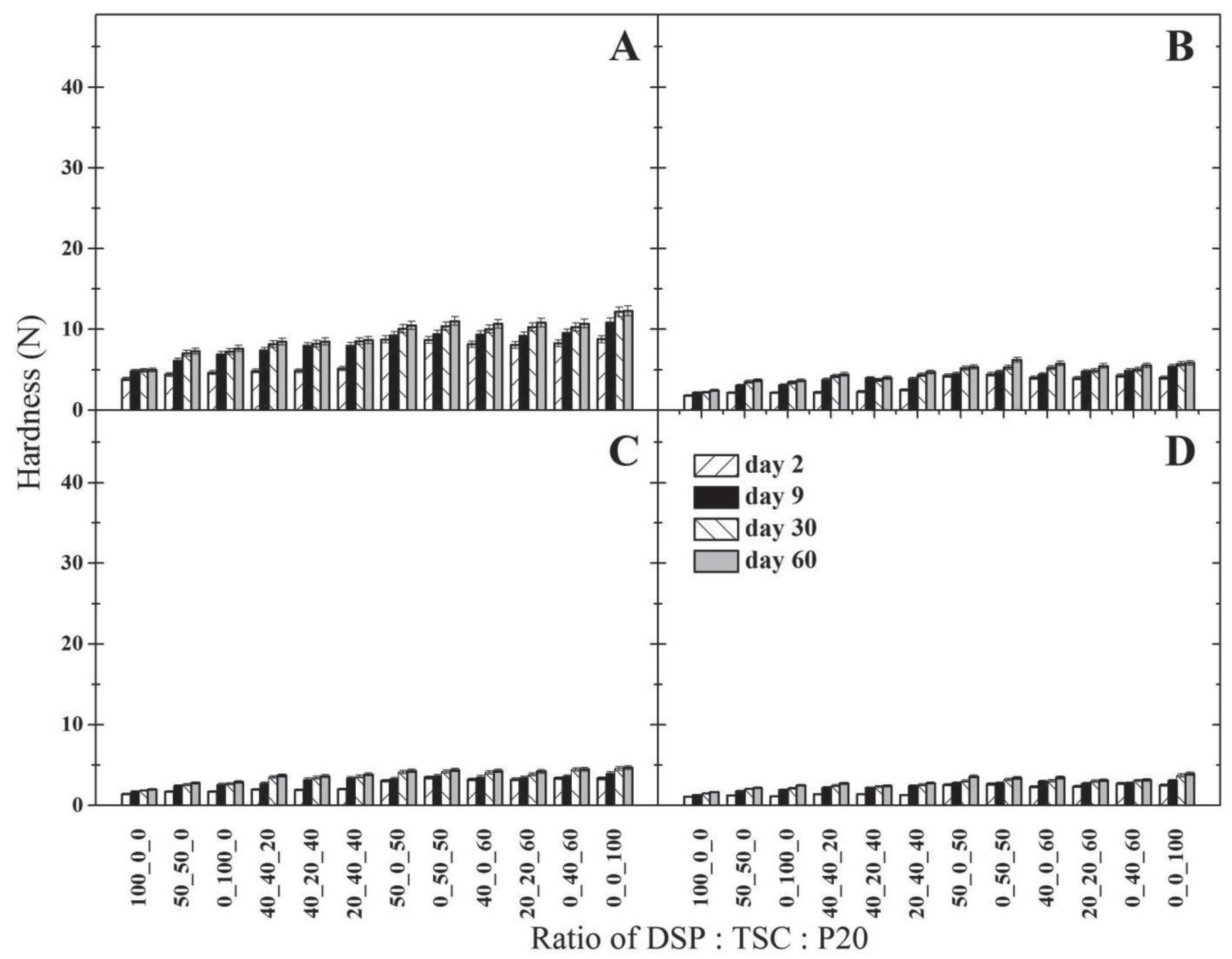

Figure 4. The dependence of processed cheese hardness (calculated as maximum force during the first penetration cycle; N) on the relative amount (in percentage; percentage of ternary mixtures was calculated on the total weight of emulsifying salts $=100 \%$; axis $\mathrm{x}$ ) of disodium phosphate (DSP), trisodium citrate (TSC), and sodium salt of polyphosphate (P20) in a ternary mixture of emulsifying salts during $60 \mathrm{~d}$ of storage at $6^{\circ} \mathrm{C}[\mathrm{n}=6$; the results were expressed as means (columns) \pm standard deviations (bars); processed cheeses were sampled after 2,9 , 30, and $60 \mathrm{~d}$ of storage]. Processed cheeses were made from Swiss-type cheese after different times of ripening (part A, 4 wk; part B, 8 wk; part C, 12 wk; part D, 16 wk). 
pan and Lucey (2011). It is based on the ability of monophosphates to amplify the development of bridges among diphosphates, calcium ions, and casein. The observed decrease in $\mathrm{PC}$ hardness in the ternary mixture of DSP, TSPP, and P20 when the proportion of P20 was increased could be caused by the ability of polyphosphates to charge casein with multiple negative ions, which leads to lower-intensity hydrophobic interactions between the dispersed casein (Mizuno and Lucey, 2007; Buňka et al., 2013; Salek et al., 2015). Furthermore, the specific ratio of TSPP:TSC (1:1) resulted in increasing hardness of the samples (Figures 2 and 4). According to the available literature, a clear answer has still not been found elucidating this phenomenon with respect to the interactions occurring between TSPP and TSC and their influence on the development of casein matrix. In addition, an analogous phenomenon was reported in the work of Salek et al. (2015). However, TSC does not appear to have the ability to create new networks and thus the influence of TSPP on casein crosslinking would not be affected by the presence of TSC ( $\mathrm{Lu}$ et al., 2007; Mizuno and Lucey, 2007; Kaliappan and Lucey, 2011). The PC samples were produced using STC with 4 different maturity degrees $(4,8,12$, and $16 \mathrm{wk}$ of ripening). The hardness of the samples obtained decreased with the increasing maturity degree of the STC

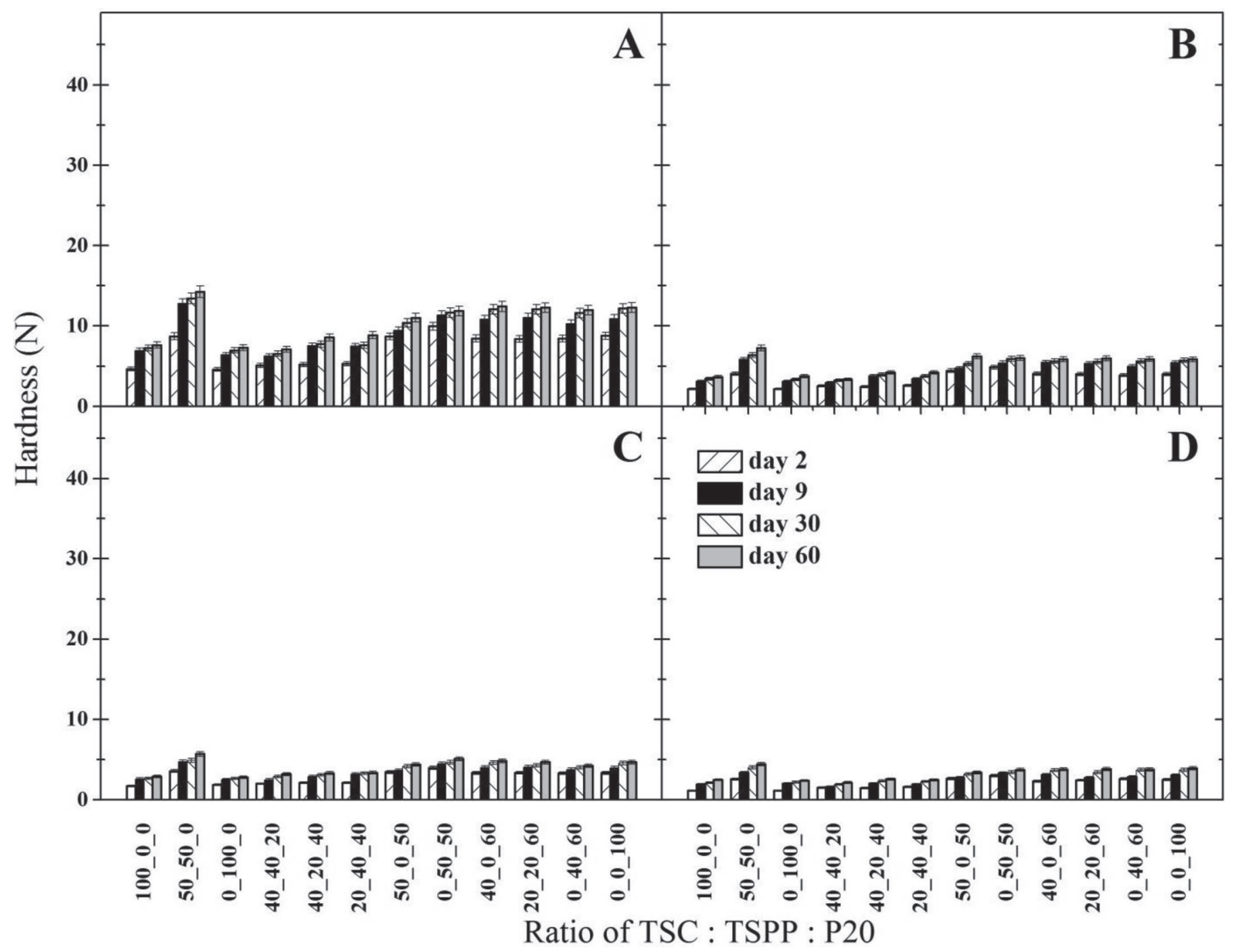

Figure 5. The dependence of processed cheese hardness (calculated as maximum force during the first penetration cycle; N) on the relative amount (in percentage; percentage of ternary mixtures was calculated on the total weight of emulsifying salts $=100 \%$; axis $\mathrm{x}$ ) of trisodium citrate (TSC), tetrasodium diphosphate (TSPP), and sodium salt of polyphosphate (P20) in a ternary mixture of emulsifying salts during 60 d of storage at $6^{\circ} \mathrm{C}[\mathrm{n}=6$; the results were expressed as means (columns) \pm standard deviations (bars); processed cheeses were sampled after 2, 9, 30, and $60 \mathrm{~d}$ of storage]. Processed cheeses were made from Swiss-type cheese after different time of ripening (part A, 4 wk; part B, 8 wk; part C, $12 \mathrm{wk}$; part D, $16 \mathrm{wk})$. 
used, regardless of the ternary mixture of ES applied. Moreover, in all of the cases (different types of ternary mixtures of ES), the trends of hardness development were similar and only the absolute values were different. Additionally, a more extensive course of proteolysis occurs with an increasing ripening period. Therefore,

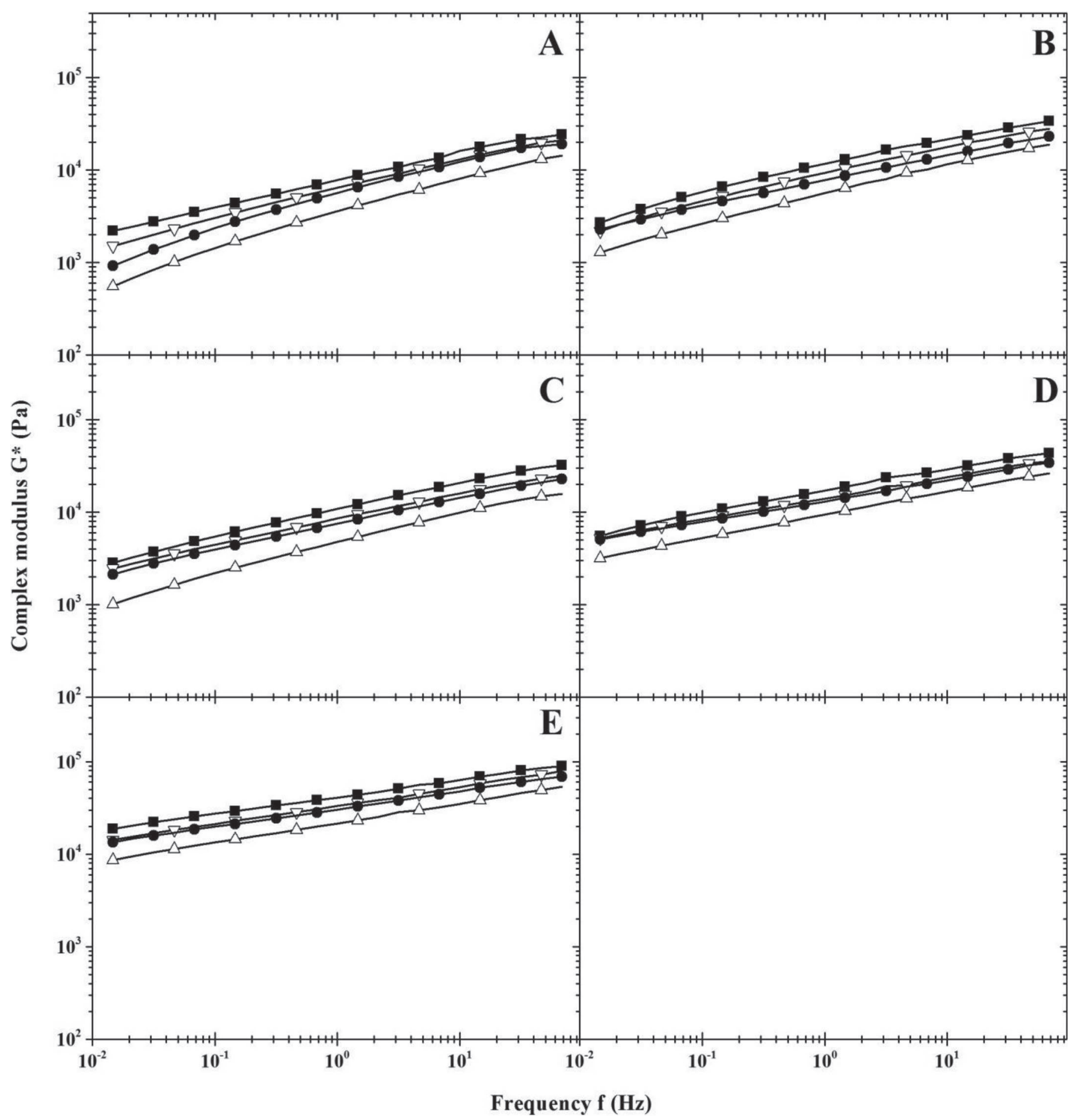

Figure 6. The dependence of complex modulus $\left(\mathrm{G}^{*}\right)$ of processed cheese (after $30 \mathrm{~d}$ of storage) made from Swiss-type cheese after different time of ripening ( 4 wk; $\nabla 8$ wk; 12 wk; $\Delta 16$ wk) on frequency (f; in range of $0.01-100.00 \mathrm{~Hz}$ ). Processed cheeses were manufactured using disodium phosphate (DSP; part A), tetrasodium diphosphate (TSPP; part B), trisodium citrate (TSC; part C), sodium salt of polyphosphate (P20; part D), or binary mixture of DSP and TSPP in ratio of 1:1 (part E). 
the casein chains of shorter average length affect the properties of the final product [i.e., a final product with less compact casein matrix may be formed (Piska and Štětina, 2004; Brickley et al., 2007; Hladká et al.,
2014)]. On the contrary, the hardness of all PC samples increased significantly with an increasing storage period (regardless of the ES ternary mixture applied and the maturity degree of STC). This current tendency of

Table 1. Values of gel strength $\left(\mathrm{A}_{\mathrm{F}} ; \mathrm{kPa} \cdot \mathrm{s}^{1 / \mathrm{z}}\right)$ of processed cheese (after 30-d storage) made from Swiss-type cheese after different times of ripening $(4,8,12 \text {, and } 16 \mathrm{wk})^{2}$

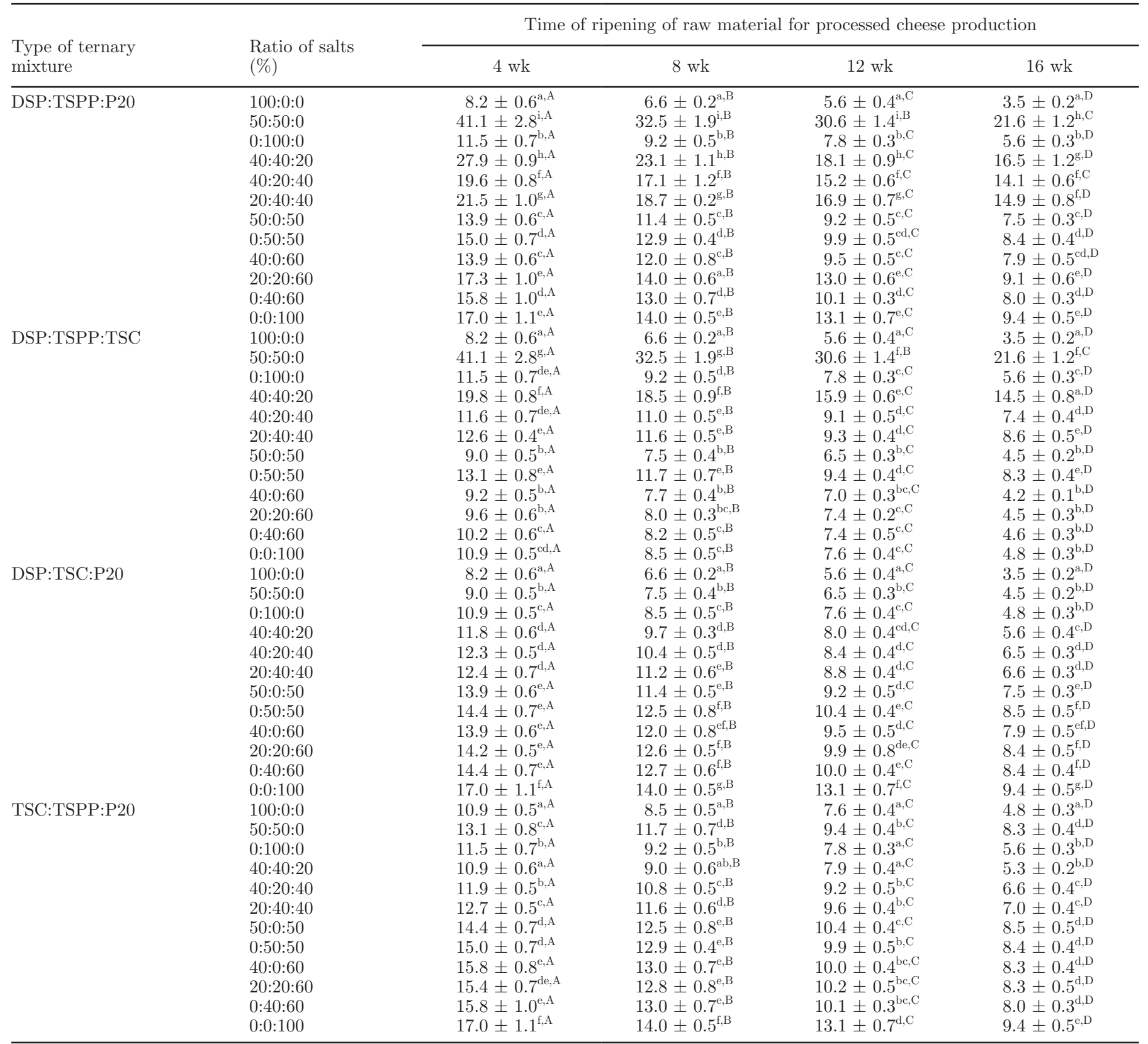

\footnotetext{
${ }^{\mathrm{a}-\mathrm{i}}$ The means within a column (the difference between samples with different ratio of emulsifying salts in the ternary mixture) followed by different superscript letters differ $(P<0.05)$; samples with each type of the ternary mixture (DSP:TSPP:P20, DSP:TSPP:TSC, DSP:TSC:P20, and TSC:TSPP:P20) were evaluated independently.

${ }^{A-D}$ The means within a row (the difference between samples with various times of Swiss-type cheese ripening) followed by different uppercase letters differ $(P<0.05)$; samples with each ratio of emulsifying salts in each ternary mixture were evaluated independently.

${ }^{1}$ Different ternary mixtures of emulsifying salts [disodium phosphate (DSP), tetrasodium diphosphate (TSPP), sodium salt of polyphosphate (P20), and trisodium citrate (TSC)] were used for manufacture of model samples. Amount of individual emulsifying salts in ternary mixture were expressed in percentage (percentage of ternary mixtures was calculated on the total weight of emulsifying salts $=100 \%$ ).
} 
Table 2. Values of interaction factor $(\mathrm{z})$ of processed cheese (after 30-d storage) made from Swiss-type cheese after different times of ripening $(4,8,12 \text {, and } 16 \mathrm{wk})^{1}$

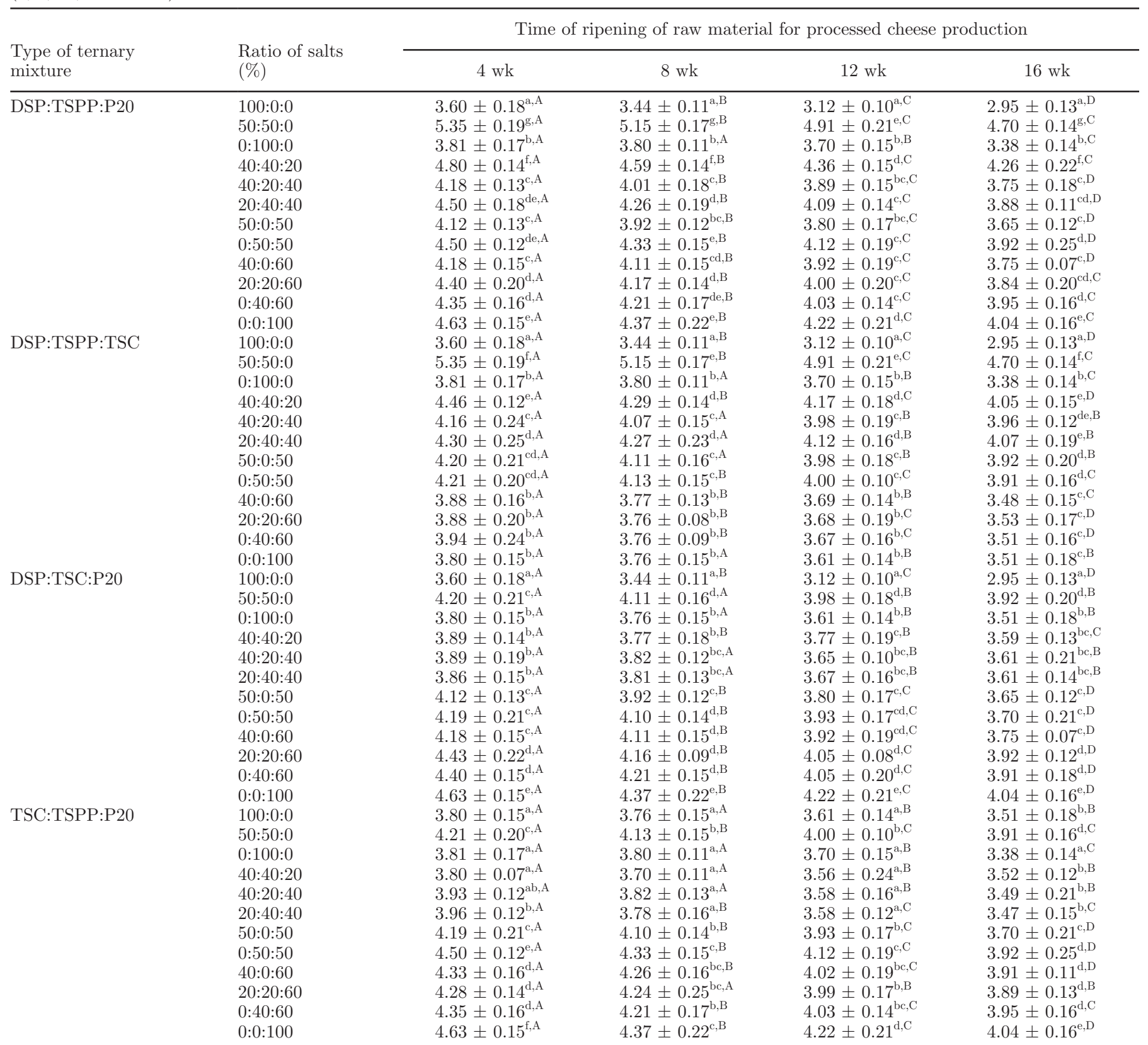

\footnotetext{
${ }^{\mathrm{a}-\mathrm{g}}$ The means within a column (the difference between samples with different ratio of emulsifying salts in the ternary mixture) followed by different lowercase letters differ $(P<0.05)$; samples with each type of the ternary mixture (DSP:TSPP:P20; DSP:TSPP:TSC; DSP:TSC:P20; TSC:TSPP:P20 were evaluated independently.

${ }^{A-D}$ The means within a line (the difference between samples with various times of Swiss-type cheese ripening) followed by different uppercase letters differ $(P<0.05)$; samples with each ratio of emulsifying salts in each ternary mixture were evaluated independently.

${ }^{1}$ Different ternary mixtures of emulsifying salts [disodium phosphate (DSP), tetrasodium diphosphate (TSPP), sodium salt of polyphosphate (P20), and trisodium citrate (TSC)] were used for manufacture of model samples. Amount of individual emulsifying salts in ternary mixture were expressed in percentage (percentage of ternary mixtures was calculated on the total weight of emulsifying salts $=100 \%$ ).
}

hardness development could mainly be elucidated in the hydrolysis of ES (with 2 or more phosphorus atoms in a molecule) and related to the protein matrix formation. Also, another possible explanation may lie in the changes in the binding forms of the ES present, leading to an adjustment to their characteristics of dissociation (Guinee et al., 2004; Shirashoji et al., 2006; Weiserová et al., 2011). The results of TPA were confirmed by 
those of the rheological analysis. Likewise, higher values of the complex modulus $\left(\mathrm{G}^{*}\right)$ indicate the increase in firmness of the $\mathrm{PC}$ samples. Furthermore, these data of the complex modulus $\left(\mathrm{G}^{*}\right)$ of $\mathrm{PC}$ were also in accordance with those obtained from Winter's critical gel theory. The higher monitored values of the gel strength can probably be explained by more intensive interactions occurring in the PC samples (the values of the interaction factor are shown in Table 2) such as hydrogen bonds, hydrophobic interactions between caseins and fat or calcium-intervened electrostatic bonds among caseins, leading to the formation of a "denser" (more intensive) network structure. On the other hand, the reduced values of the gel strength observed during STC course of proteolysis could have been caused by a drop in the number of interactions in the PC matrix (Černíková et al., 2008; Kapoor and Metzger, 2008). Presumably, the novelty of this work lies in the fact that the textural and rheological properties of the PC manufactured from STC of different degrees of maturity and different composition of ES ternary mixtures have not been found in the literature.

\section{CONCLUSIONS}

The application of the binary mixture of DSP:TSPP (in a ratio of 1:1) resulted in products with the highest values of hardness (regardless of the maturity degree of the STC applied). Furthermore, the hardness of the samples obtained decreased with the rising maturity degree of the STC used (regardless of the ES mixture applied). However, on the contrary, the hardness of all PC samples increased with prolonging the storage period. Admittedly, the results of TPA corresponded to those of the rheological analysis. The highest overall rigidity $\left(G^{*}\right)$, gel strength, and interaction factor values were found in the samples prepared with DSP:TSPP (1:1), followed by the samples prepared with P20, TSPP, TSC, and DSP, respectively. The monitored values of the gel strength and interaction factor decreased with the increasing maturity degree of the STC used. The intensity of rigidity of the PC samples has an analogous relationship to the intensity of the gel strength; the higher the gel strength of the sample, the more inflexible the product that can be expected.

\section{ACKNOWLEDGMENTS}

This study was kindly supported by a project of the internal grants of Tomas Bata University in Zlin, Czech Republic, no. IGA/FT/2014/001 and IGA/ FT/2015/004 funded from the resources of specific university research.

\section{REFERENCES}

Beuvier, E., K. Berthaud, S. Cegarra, A. Dasen, S. Pochet, S. Buchin, and G. Duboz. 1997. Ripening and quality of Swiss-type cheese made from raw, pasteurized or microfiltered milk. Int. Dairy J. $7: 311-323$.

Bouton, Y., S. Buchin, G. Duboz, S. Pochet, and E. Beuvier. 2009. Effect of mesophilic lactobacilli and enterococci adjunct cultures on the final characteristics of a microfiltered milk Swiss-type cheese. Food Microbiol. 26:183-191.

Brickley, C. A., M. A. E. Auty, P. Piraino, and P. L. H. McSweeney. 2007. The effect of natural Cheddar cheese ripening on the functional and textural properties of the processed cheese manufactured therefrom. J. Food Sci. 72:C483-C490.

Buňka, F., L. Doudová, E. Weiserová, D. Kuchař, J. Michálek, S. Slavíková, and S. Kráčmar. 2012. The effect of different ternary mixtures of sodium phosphates on hardness of processed cheese spreads. Int. J. Food Sci. Technol. 47:2063-2071.

Buňka, F., L. Doudová, E. Weiserová, D. Kuchař, P. Ponížil, D. Začalová, G. Nagyová, V. Pachlová, and J. Michálek. 2013. The effect of ternary emulsifying salt composition and cheese maturity on the textural properties of processed cheese. Int. Dairy J. 29:1-7.

Buňka, F., L., E. Doudová, M. Weiserová, D. Černíková, S. Kuchař, G Slavíková, P. Nagyováa, T. Ponížile, Grůberd, and J. Michálek. 2014. The effect of concentration and composition of ternary emulsifying salts on the textural properties of processed cheese spreads. LWT Food Sci. Technol. 58:247-255.

Buňková, L., F. Buňka, M. Hlobilová, Z. Vaňatková, D. Nováková, and V. Dráb. 2009. Tyramine production of technological important strains of Lactobacillus, Lactococcus and Streptococcus. Eur. Food Res. Technol. 229:533-538.

Bustamante, M. A., M. Virto, M. Aramburu, L. J. R. Barron, F. J. Pérez-Elortondo, M. Albisu, and M. de Renobles. 2003. Lamb rennet paste in ovine cheese (Idiazabal) manufacture. Proteolysis and relationship between analytical and sensory parameters. Int. Dairy J. 13:547-557.

Černíková, M., F. Buňka, V. Pavlínek, P. Březina, J. Hrabě, and P. Valášek. 2008. Effect of carrageenan type on viscoelastic properties of processed cheese. Food Hydrocoll. 22:1054-1061.

Chen, L., and H. Liu. 2012. Effect of emulsifying salts on the physicochemical properties of processed cheese made from Mozzarella. J. Dairy Sci. 95:4823-4830.

Cunha, C. R., R. Grimaldi, M. R. Alcântara, and W. H. Viotto. 2013 Effect of the type of fat on rheology, functional properties and sensory acceptance of spreadable cheese analogue. Int. J. Dairy Technol. 66:54-62.

Dimitreli, G., and A. S. Thomareis. 2007. Texture evaluation of blocktype processed cheese as a function of chemical composition and in relation to its apparent viscosity. J. Food Eng. 79:1364-1373.

Dimitreli, G., and A. S. Thomareis. 2009. Instrumental textural and viscoelastic properties of processed cheese as affected by emulsifying salts and in relation to its apparent viscosity. Int. J. Food Prop. 12:261-275.

El-Bakry, M., E. Duggan, E. D. O'Riordan, and M. O'Sullivan. 2011. Effect of chelating salt type on casein hydration and fat emulsification during manufacture and post-manufacture functionality of imitation cheese. J. Food Eng. 102:145-153.

Gabriele, D., B. de Cindio, and P. D'Antona. 2001. A weak gel model for foods. Rheol. Acta 40:120-127.

Guinee, T. P., M. Carić, and M. Kaláb. 2004. Pasteurized processed cheese and substitute/imitation cheese products. Pages 349-394 in Cheese: Chemistry, Physics and Microbiology. Major Cheese Groups. Vol. 2. P. F. Fox, P. L. H. McSweeney, and T. P. Cogan, ed. Elsevier Applied Science, London, UK.

Gustaw, W., and S. Mleko. 2007. The effect of polysaccharides and sodium chloride on physical properties of processed cheese analogs containing whey proteins. Milchwissenschaft 62:59-62.

Hanaei, F., G. Cuvelier, and J. M. Sieffermann. 2015. Consumer texture descriptions of a set of processed cheese. Food Qual. Prefer. $40: 316-325$. 
Hayaloglu, A. A., M. Guven, P. F. Fox, J. A. Hannon, and P. L. H. McSweeney. 2004. Proteolysis in Turkish White-brined cheese made with defined strains of Lactococcus. Int. Dairy J. 14:599-610.

Hladká, K., Z. Randulová, B. Tremlová, P. Ponížil, P. Mančík, M. Černíková, and F. Buňka. 2014. The effect of cheese maturity on selected properties of processed cheese without traditional emulsifying agents. LWT Food Sci. Technol. 55:650-656.

ISO (International Organization for Standardization). 2004. ISO Standard No. 5534: Cheese and processed cheese-Determination of the total solid content (reference method). ISO, Geneva, Switzerland.

Ji, T., V. B. Alvarez, and W. J. Harper. 2004. Influence of starter culture ratios and warm room treatment on free fatty acid and amino acid in Swiss cheese. J. Dairy Sci. 87:1986-1992.

Kaliappan, S., and J. A. Lucey. 2011. Influence of mixtures of calcium-chelating salts on the physicochemical properties of casein micelles. J. Dairy Sci. 94:4255-4263.

Kapoor, R., and L. E. Metzger. 2008. Process cheese: Scientific and technological aspects-A review. Comp. Rev. Food Sci. Food Safety $7: 194-214$

Kawasaki, Y. 2008. Influence of "creaming" on the properties of processed cheese and changes in the structure of casein during cheese making. Milchwissenschaft 63:149-153.

Lee, S. K., S. Anema, and H. Klostermeyer. 2004. The influence of moisture content on the rheological properties of processed cheese spreads. Int. J. Food Sci. Technol. 39:763-771.

Lee, S. K., R. J. Buwalda, S. R. Euston, E. A. Foegeding, and A. B. McKennan. 2003. Changes in the rheology and microstructure of processed cheese during cooking. LWT Food Sci. Technol. 36:339345 .

Lee, S. K., M. Huss, H. Klostermeyer, and S. G. Anema. 2013. The eefect of pre-denatured whey proteins on the textural and microstructural properties of model processed cheese spreads. Int. Dairy J. 32:79-88.

Lee, S. K., and H. Klostermeyer. 2001. The effect of pH on the rheological properties of reduced-fat model processed cheese spreads. LWT Food Sci. Technol. 34:288-292.

Lu, Y., N. Shirashoji, and J. A. Lucey. 2007. Rheological, textural and melting properties of commercial samples of some of the different types of pasteurized processed cheese. Int. J. Dairy Technol. 60:74-80.

Macků, I., F. Buňka, B. Voldánová, and V. Pavlínek. 2009. Effect of addition of selected cosolutes on viscoelastic properties of model processed cheese containing pectin. Food Hydrocoll. 23:2078-2084.

Marchesseau, S., E. Gastaldi, A. Lagaude, and J. L. Cuq. 1997. Influence of $\mathrm{pH}$ on protein interactions and microstructure of process cheese. J. Dairy Sci. 80:1483-1489.

Martínez-Ruvalcaba, A., E. Chornet, and D. Rodrigue. 2007. Viscoelastic properties of dispersed chitosan/xanthan hydrogels. Carbohydr. Polym. 67:586-595.

Mizuno, R., and J. A. Lucey. 2007. Properties of milk protein gels formed by phosphates. J. Dairy Sci. 90:4524-4531.

Nagyová, G., F. Buňka, R. N. Salek, M. Cerníková, P. Mančík, T. Grůber, and D. Kuchař. 2014. Use of sodium polyphosphates with different linear lengths in the production of spreadable processed cheese. J. Dairy Sci. 97:111-122.

Ochi, H., Y. Sakai, H. Koisihara, F. Abe, T. Bamba, and E. Fukusaki. 2013. Monitoring the ripening process of Cheddar cheese based on hydrophilic component profiling using gas chromatography-mass spectrometry. J. Dairy Sci. 96:7427-7441.

Pachlová, V., F. Buňka, L. Buňková, E. Weiserová, P. Budinský, M. Žaludek, and S. Kráčmar. 2011. The effect of three different ripening/storage conditions on distribution of selected parameters in individual parts of Dutch-type cheese. Int. J. Food Sci. Technol. 46:101-108

Pachlová, V., F. Buňka, R. Flasarová, P. Válková, and L. Buňková. 2012. The effect of elevated temperature on ripening of Dutch type cheese. Food Chem. 132:1846-1876.

Paulsen, P. V., J. Kowalewska, E. G. Hammond, and B. A. Glatz. 1980. Role of microflora in production of free fatty acids and flavor in Swiss cheese. J. Dairy Sci. 63:912-918.

Piska, I., and J. Stětina. 2004. Influence of cheese ripening and rate of cooling of the processed cheese mixture on rheological properties of processed cheese. J. Food Eng. 61:551-555.

Poveda, J. M., L. Cabezas, and P. L. H. McSweeney. 2004. Free amino acid content of Manchego cheese manufactured with different starter cultures and changes throughout ripening. Food Chem. $84: 213-218$.

Sádlíková, I., F. Buňka, P. Budinský, B. Voldánová, V. Pavlínek, and I. Hoza. 2010. The effect of selected phosphate emulsifying salts on viscoelastic properties of processed cheese. LWT Food Sci. Technol. 43:1220-1225.

Salek, R. N., M. Černíková, G. Nagyová, D. Kuchař, H. Bačová, L. Minarčíková, and F. Buňka. 2015. The effect of composition of ternary mistures containing phosphate and citrate emulsifying salts on selected textural properties of spreadable processed cheese. Int. Dairy J. 44:37-43.

Shirashoji, N., J. J. Jaeggi, and J. A. Lucey. 2006. Effect of trisodium citrate concetration and cooking time on the physicochemical properties of pasteurized processed cheese. J. Dairy Sci. 89:15-28.

Sołowiej, B., I. W. Y. Cheung, and E. C. Y. Li-Chan. 2014. Texture, rheology and meltability of processed cheese analogues prepared using rennet or acid casein with or without added whey proteins. Int. Dairy J. 37:87-94.

Vicente, M. S., F. C. Ibáñez, Y. Barcina, and L. J. R. Barron. 2001. Changes in the free amino acid content during ripening of Idiazabal cheese: Influence of starter and rennet type. Food Chem. 72:309-317.

Weiserová, E., L., L. Doudová, L. Galiová, J. Žák, R. Michálek, Janiš, and F. Buňka. 2011. The effect of combinations of sodium phosphates in binary mixtures on selected texture parameters of processed cheese spreads. Int. Dairy J. 21:979-986.

Winter, H. H., and F. Chambon. 1986. Analysis of linear viscoelasticity of a crosslinking polymer at the gel point. J. Rheol. (N.Y.N.Y.) 30:367-382. 